\title{
A Deep Look into Interactional Pathology among Couples with Morbidly Jealous Male Partners: A Phenomenological Study
}

\author{
Marzieh Soltani ${ }^{1}$, Maryam Fatehizade ${ }^{2}$, Ahmad Ahmadi ${ }^{3}$, Mohammad reza Abedi $^{3}$, \\ Rezvan Jazayeri ${ }^{4} \&$ Mehrdad Salehi ${ }^{5}$ \\ ${ }^{1}$ PhD student, Department of Counseling, Faculty of Education and Psychology, University of Isfahan, Isfahan, \\ Iran \\ ${ }^{2}$ Associate Professor, Department of Counseling, Faculty of Education and Psychology, University of Isfahan, \\ Isfahan, Iran \\ ${ }^{3}$ Professor, Department of Counseling, Faculty of Education and Psychology, University of Isfahan, Isfahan, Iran \\ ${ }^{4}$ Assistant Professor, Department of Counseling, Faculty of Education and Psychology, University of Isfahan, \\ Isfahan, Iran. \\ ${ }^{5}$ Associate Professor, Isfahan University of Medical Science, Isfahan, Iran \\ Correspondence: Maryam Fatehizade, Department of Counseling, Faculty of Education and Psychology, \\ University of Isfahan, Isfahan, Iran. Phone: 98-313-793-2615. E-mail: m.Fatehizade@edu.ui.ac.ir
}

Received: September 28, 2016 Accepted: June 6, 2017 Online Published: July 17, 2017

doi:10.5539/gjhs.v9n9p116

URL: https://doi.org/10.5539/gjhs.v9n9p116

\begin{abstract}
The purpose of this phenomenological study was to gain a deeper understanding of interactional pathology among couples with the morbidly jealous male partners by examining the lived experiences of 5 female partners. The study attempted to answer the main research question which was, "How do women experience their communication with their morbidly jealous husbands?" along with some sub questions in different dimensions of marital life. The major data collection tool consisted of semi-structured interviews (Seidman, 2013). Forty to sixty-minute interviews were conducted with each participant. Data analysis included a three-phase process: description, reduction, and interpretation. The latter was completed using the qualitative content analysis by Colaizzi (Colaizzi, 1973). Four categories of lived experiences indicating interactional difficulty among the couples were obtained from the data analysis. These interactional damageswere evident in the experiences of all the women interviewed and consisted of themes related to boundaries, control, intimacy and 'meta-damages'. The results of the study revealed that the damages begin with those related to boundaries, develop to control and intimacy rooted in meta-damages and finally terminate marital relationships.
\end{abstract}

Keywords: lived experiences, morbidly jealous husbands, interactional damages, partners, pathology

\section{Introduction}

The foundation of every family is communication between couples. Indeed, good communication is the foundation of a strong marriage. Many marriages could be saved if spouses improved the ways they communicate with each other. Many theories have attended to couple communication (e.g. Baxter, 1988; Blaisure \& Allen, 1995; Bochner, 1985; Burr, 1973; Canary \& Stafford, 1992). Couple communication may be impaired by different factors such as the role of gender, age of marriage, low education (Bumpass, Martin, and Sweet, 1991), distancing behavior (Roberts, 2000), and genetics (McGue \& Lykken, 1992; Jocklin et al., 1996). Storaasli and Markman (1990) found that women considered money and issues with relatives as more intense problems in their relationships, while men reported children as a more intense problem. Amato and DeBoer (2011) believed marital dissolution is related to the level of conflict in the marriage and Stieglitz et al. (2012) attended to infidelity and jealousy in marital conflict. The present study is interested in the type of jealousy that can be described as morbid jealousy and the communication damages experienced by women who have a morbidly jealous partner.

In this context, morbid jealousy can be what leads to marital conflicts. Morbid jealousy refers to negative emotions and 'irrational' thoughts such as spouse infidelity. Together, they stimulate unacceptable behavior, in which the main problem is rumination of one partner on the faithfulness of the other based on unsubstantiated evidence (Cobb, 1979). Mullen (1990) introduced four features for morbid jealousy, i.e., an underlying mental disorder 
appear before or with the jealousy; the underlying disorder coexist with the jealousy; the course of morbid jealousy closely relates to that of the underlying disorder; and the jealousy has no root in reality (Mullen, 1990). (It may be helpful to give examples of each-this is excellent examples!)

Vauhkonen (1968) believed that jealousy in normal people occurs in response to firm evidence, i.e., they are, though difficult, ready to change their beliefs and reactions when new information becomes available, and perceive a single rival. In contrast, for morbidly jealous individuals irrelevant occurrences would be conclusive evidence of infidelity by which refuse to change their beliefs even when they encounter conflicting information, and thus accuse the partner of infidelity.

Some researchers point out to delusions and obsessions among individuals with morbid jealousy (e.g. Enoch \& Trethowan, 1979; Shepherd, 1961). Infidelity delusions can be seen in both delusional disorders and schizophrenia. In schizophrenia, these delusions are persecutory delusions in which, for example, the partner thinks her/his partner is being poisoned to reduce sexual potency, but in delusional disorders the delusions of infidelity are without any other pathological features (Kingham \& Gordon, 2004). Stein et al. (1994) regarded obsessional jealousy as associated with shame and discomfort. Kingham and Gordon (2004) introduced delusions in morbid jealousy with some characteristics which exist in one's own thought, are ego-syntonic, regarded as true, but not resisted. Obsessions in morbid jealousy, on the other hand, are characterized by being in one's own thought, ego-dystonic, acknowledged to be senseless, and usually resisted

Marazziti et al (2003) introduced differential diagnosis criteria for obsessional jealousy of which the following are more severe: Time taken up by jealous concerns, difficulty in putting the concerns out of the mind, impairment of the relationship, limitation of the partner's freedom, and checking on the partner's behavior. Kingham and Gordon (2004) believed morbid jealousy may appear as an overvalued delusion, obsession or a combination of both. Therefore, it is a symptom rather than a diagnosis.

Many researchers have attended to emotion in marital communication. For example, Bloch, Hasse and Levenson (2014) showed downregulation of negative emotions during marital conflicts leads to marital satisfaction and more constructive communication. Sanford (2012) attends to emotional encoding and decoding between couples. "A clearly encoded emotion can be defined as one that is expressed with sufficient clarity so that it is recognized by outside observers. In contrast, emotion decoding via objective observation occurs when a person recognizes an emotion that was expressed overtly by his or her partner. This can be defined as perceiving the same emotion in a partner as that which is perceived by outside observers" (p. 1). Iveniuk et al. (2014) showed high neuroticism and low positivity of men are associated with more conflict among couples. Randall et al. (2013) showed the association between marital cooperation and emotional coordination. Malouff et al. (2014) showed a positive and significant association between emotion intelligence and romantic relationship satisfaction. He also found that a significant relationship between an individual's emotional intelligence and the partner's level of satisfaction with the relationship In Iran aslo some researchers have investigated the role of emotion in marital life. Rajabi, Mousavian Nejad and Taghi Pour (2014) found emotion was significantly and positively associated with marital satisfaction but significantly and negatively related to conflict. Gharehbaghy Aguilar-Vafaie (2010) examined the relationship between emotional security and role conflict. Pirsaghi et al. (2015) reported a significant association between emotional schema and marital conflict Although many studies have examined the role of emotion in marital life, there is no research on morbid jealousy in men and its effects on their communication with their spouses.

Taking into account the previous research in this area, therapeutic actions in family therapy need more knowledge about communication pathology women experience in living with husbands who suffer from morbid jealousy symptoms. Findings of the present study would help to fill the knowledge gap in the literature regarding morbid jealousy and compensate lack of research on exact communication pathology. Considering what was mentioned above, the present study aimed at answering the question: what are the interactive damages incurred among couples with a morbidly jealous husband?

\section{Method}

This study was a phenomenological qualitative study. Phenomenology is the study of experiences of phenomena and structure thereof, which analyses form individuals' point of view (Moustakas, 1994). Five female participants were recruited through the use of purposeful sampling methods. The present study attempted to establish a good correspondence between the research question and the sampling (Bryman, 2004). The inclusion criteria were formed based on currently married participants who have been married for at least one year or more to a morbidly jealous spouse. It needs to be mentioned that the individuals aged 24 to 35 were interviewed. The reason for age restriction was to form a more coherent group and, thus, make comparison between the subjects more relevant. 
Table 1 shows the demographic characteristics. The participants were required to meet the following inclusion criteria: (a) the participant can understand the researchers' questions; (b) they have no acute and chronic physical illnesses or mental disorders; (c) they are willing to participate and able to provide information.

Table 1. Demographic characteristics of participants

\begin{tabular}{lllll}
\hline Participant & Age & Marital status & NO. of Children & The length of marriage \\
\hline 1 & 33 & Married & 2 (one boy and one girl) & 13 years \\
2 & 34 & Married & 2 (one boy and one girl) & 18 years \\
3 & 26 & Married & - & 1 year \\
4 & 35 & Married & 3 (one boy and two girls) & 19 years \\
5 & 24 & Married & - & 1 year \\
\hline
\end{tabular}

The transcripts and tape recordings were not labeled with participants' names to maintain confidentiality throughout all stages of the study. Ethical approval was obtained from the ethical committee of Isfahan University as well

Data collection was conducted using a semi-structured interview. The questions were mainly open ended questions with a small number of closed questions relating to information such as age, the length of the marriage and number of children and so on. The interviewer could ask additional exploring questions in response to what are viewed as significant replies only after sufficient rapport and empathy were developed between the researcher and the participant. Each participant was presented with a similar set of questions relating to their overall experiences of living with a morbidly jealous husband and the impact it had on their interaction and communication. An example of an open ended question included in the interview schedule is: "What are your main problems with your husband in your marital life?" The researchers attempted to use language that was comprehensible and relevant to each participant. Data collection continued until data saturation. All interviews were recorded and transcribed and each interview was assigned a code. Then, the researchers listened to the recordings and made notes. Key words, phrases, and statement were transcribed. The seven-stepmethod of Colaizzi (1978) was used to analyze the data as follows:

1) The researchers read all participants' descriptions and tried to empathize with them.

2) To extract important themes, the researchers found the related words, phrases and sentences, and coded them afterwards.

3) All the extracted codes were given formulated meaning.

4) The formulated meanings were organized into clusters of themes. To make them reliable, the researchers checked the main descriptions.

5) Results were then integrated into an exhaustive description of the phenomenon under study.

6) The exhaustive description of the investigated phenomenon was formulated as an unequivocal statement of identification when possible.

7) Finally, to clarify the acquired ideas and make them reliable, the findings were referred back to the participants for the validity approval.

To evaluate the credibility of data analysis, the researchers had numerous negotiations until agreements were achieved on each aspect of the process. Then, an expert in phenomenological method reviewed the analysis of data and confirmed that appropriate procedure had been followed.

For the validity and reliability of data analysis and with reference to Golafshani (2003), the researchers had numerous negotiations until agreements were achieved on each aspect of the process. To provide details of the method and abundance of evidence and triangulation, the extracted themes were examined from a family therapist's perspective. Also an expert in the phenomenological method reviewed the analysis of data and confirmed that appropriate procedure had been followed. Logical connections between data and conclusions were obtained by the researchers as well.

\section{Results}

A total of 306 conceptual codes, 4 themes and 27 subthemes were extracted through the analysis of the interviews. 
Table 2 shows the main themes and subthemes derived from experiences of the participants who lived with morbidly jealous husbands/ a morbidly jealous husband.

Table 2. The main themes and sub- themes along with one example for each sub-theme that is derived from the participants' experiences with a morbidly jealous husband

\begin{tabular}{|c|c|c|}
\hline Number of Codes & Themes & Subthemes \\
\hline 65 & $\begin{array}{l}\text { Damages related to } \\
\text { boundaries }\end{array}$ & $\begin{array}{l}\text { Intense emotions at the beginning of the relationship } \\
\text { Improper handling } \\
\text { Restricting the means of communication } \\
\text { Dependenc } \\
\text { Expressing emotions without considering privacy } \\
\text { Rigid boundaries } \\
\text { Distrusting others } \\
\text { Poor intergenerational boundaries }\end{array}$ \\
\hline 63 & $\begin{array}{lll}\text { Damages related to } \\
\text { intimacy }\end{array}$ & $\begin{array}{l}\text { Inappropriate sexual intimacy } \\
\text { Inappropriate affective intimacy } \\
\text { Inappropriate intellectual intimacy } \\
\text { Inappropriate practical intimacy } \\
\text { Inappropriate physical intimacy } \\
\text { Inappropriate intimacy with children }\end{array}$ \\
\hline 116 & $\begin{array}{l}\text { Damages related to } \\
\text { control }\end{array}$ & $\begin{array}{l}\text { Control through unreasonable demands) } \\
\text { Control through acting out anger } \\
\text { Control through creating confusion } \\
\text { Control through intrusive curiosity } \\
\text { Control through religion } \\
\text { Control through growth restriction } \\
\text { Control through contempt } \\
\text { Control through sensitivity } \\
\text { Control through revenge }\end{array}$ \\
\hline 48 & Meta-damages & $\begin{array}{l}\text { Cognitive meta-damages } \\
\text { Practical meta-damages } \\
\text { Emotional meta-damages } \\
\text { Intergenerational meta-damages }\end{array}$ \\
\hline
\end{tabular}

The themes and subthemes are presented with clarifying samples as follows:

Theme 1: Damages related to boundaries (the concept of boundaries in the present study is defined as the determining rules to let information and people into and out of the family)

One of the main themes in the experiences of women living with morbidly jealous husbands was the damages related to boundaries with nine subthemes: Intense emotions at the beginning of the relationship, improper coping, restricting the means of communication (for example?), dependency, expressing emotions without considering privacy, rigid boundaries, distrusting others, and poor intergenerational boundaries. Every subtheme is presented with one example as follows:

- Intense emotions at the beginning of the relationship (the subtheme was chosen because the reason to form that marital relation was intense emotions not contemplation). 
"We actually loved each other at the beginning of our relationship."

- Improper handling (the subtheme was chosen because the communication of the woman or couple with other people was stressful)

"He doesn't like me to go to my friends' house or visit my family. He doesn't allow me to communicate with my friends and family"

- Restricting the means of communication (the subtheme was chosen because morbidly jealous men limit their wives' access to the means of communication).

"He objects to using the internet and mobile phones."

- Dependency (the subtheme was chosen because the man cannot decide without his family)

"He needs to consult his mother about everything. When I ask him why, he says, "it is none of your business."

- Expressing emotions without considering privacy (the subtheme was chosen because the man expresses his intense emotions at any time and place)

"In the presence of our children, he beats and insults me"

- Rigid boundaries (the subtheme was chosen because the man wasn't able to establish the minimum connection)

"He has no relationship with others; his boundaries are so rigid and inflexible that nobody can get close either physically or emotionally."

- Distrustingothers (the subtheme was chosen because the man wasn't able to establish minimum trust)

"When I was alone at home I was not allowed to open the door to anyone, even her grandmother."

- Poor intergenerational boundaries (the subtheme was chosen because there are no appropriate boundaries between the extended family and nuclear family)

- " His mother is always meddling in our life."

Theme 2: Damages related to intimacy (intimacy in the present study was defined as the marital closeness between couples in different aspects of their marital life)

One of the main themes in the experience of women with morbidly jealous husbands was the damages related to intimacy with six subthemes: Inappropriate sexual intimacy, inappropriate affective intimacy, inappropriate intellectual intimacy, inappropriate practical intimacy, inappropriate physical intimacy, and inappropriate intimacy with children.

- Inappropriate sexual intimacy (the subtheme was chosen because the couple couldn't build a favorable sexual relationship for both sides)

"We have very little sex without any attention to my demands"

- Inappropriate affective intimacy (the subtheme was chosen because the couple couldn't build a favorable mutual affective relationship)

"Actually I don't know who should I talk to? He expects me to love him but he can't love me back."

- Inappropriate intellectual intimacy (the subtheme was chosen because the man couldn't make logical decision and sees his wife as second)

"He always was at his mother and sister's service but misery and discomfort were mine"

- Inappropriate practical intimacy (the subtheme was chosen because the couple weren't close enough in the management of life affairs)

"He doesn't help around the house; he has no incentive to help out."

- Inappropriate physical intimacy (the subtheme was chosen because the couple weren't able to have appropriate physical closeness)

"We prefer not to go out anywhere together because he gets on our nerves" (I am not certain if the example fits inappropriate physical intimacy)

Theme 3: Damages related to control (control in the present study is defined as the specific rules determining power division and manipulating tactics)

One of the main themes in the experience of women with morbidly jealous husbands was the damages related to 
control with nine subthemes: Control through unreasonable demands, control through acting out anger, control through creating confusion, control through curiosity, control through religion, control through growth restriction, control through contempt, control through sensitivity, and control through revenge.

- Control through unreasonable demands and expectations (the subtheme was chosen because the man manipulated his wife by intense demands)

"While we were moving forward, his demands and exceptions came up; he told me i mustn't go to my brother's house and no man should see me."

- Control through acting out anger (the subtheme was chosen because the man manipulated his wife by anger and aggression)

"He has a broadsword; he threatens us with it."

- Control through creating confusion (the subtheme was chosen because the man manipulated his wife and gained power by his vague demands)

"what he demands is not clear."

- Control through intrusive curiosity (the subtheme was chosen because the man manipulated his wife and gained power by officiousness in all affairs even in those totally personal matters related to women).

"Where are you going? Why are you going? Who do you go alone? Why do you laugh? What did that man say? Why did you wear this dress? Why did you buy it? Who called? Who was in your mother's house when you went there? He is always asking and asking the same questions."

- Control through religion (the subtheme was chosen because the man manipulated his wife and gained power by religion)

"He tells me, according to Islam, women are not allowed to go out without their husband's permission."

- Control through growth restriction/ individuation/industry (the subtheme was chosen because the man manipulated his wife and gained power by blocking he woman's progress)

"He doesn't allow me to work; he likes me to depend on him."

- Control through contempt (the subtheme was chosen because the man manipulated his wife and gained power by putting the woman down)

"On holydays when he buys me something, he tells me off."

- Control through sensitivity (the subtheme was chosen because the man manipulated his wife and gained power by being emotionally alert and overreacting to some of the woman's activities)

"He just watches that no one is close to me and I don't go anywhere."

- Control through revenge (the subtheme was chosen because the man manipulated his wife andgained power by retaliation and revenge)

"My father was sick but he didn't let me go to my father's house. He said, "your father scorned me and I never forget it."

Theme 4: Meta-damages (meta-damages in the present study are defined as the damages that cover other damages)

One of the main themes in the experience of women with morbidly jealous husbands was meta-damages with four subthemes: Cognitive meta-damages, practical meta-damages, emotional meta-damages and intergenerational meta-damages. Every subtheme is presented along with one example as follows:

- Cognitive meta-damages (the subtheme was chosen because the man had the beliefs that damaged boundaries, intimacy, and control tactics)

"women should stay at home; no one should see you; man is the boss"

- Practical meta-damages (the subtheme was chosen because the man was showing behaviors that damaged boundaries, intimacy, and control tactics)

"He can't keep secrets; he says all our marital problems to his family and his family supports him and scorns me so much that their son can dominate me."

- Emotional meta-damages (the subtheme was chosen because the man had emotions that damaged boundaries, intimacy, and control tactics) 
"He is implacable, cruel, and unjust."

- Intergenerational meta-damages (the subtheme was chosen because the man had problems in his family. For example, his parents had many conflicts)

"All his family members have problems, for example his father thinks his wife has relations with other men."

\section{Discussion}

As the researchers in the present study were interested in exploring interactional damages among couples with the morbidly jealous men, they interviewed five women living with morbid jealous husbands. They asked them to narrate their experiences of their communication with their husbands. Analysis and interpretation of their experiences revealed four types of interactional damages: Damages related to boundaries, damages related to intimacy, damages related to control, and meta-damages. Since, damages were more frequent in control dimension, the researchers concluded that the signs of morbid jealousy in men appear in boundaries theme. That is, at first the husbands have many problems in regulating their internal and external interactions and close relationships with their wife and other relatives, friends, and people. These men decrease the negative emotions of morbid jealousy by unorganized boundaries. The boundaries are rigid and extremely inflexible for their wives and extremely open and flexible for some others (e. g. he told all our life secrets to his mother). It is clear that the boundaries are extremely inflexible for their wives.

Inappropriate boundaries cause to use wrong tactics (such as wrong controlling behavior) to protect these boundaries. The goal of illogical boundaries is to limit and minimize women's communication to external world. They have to use illogical safety and security tactics that cause the control experiences of women to become bitter experiences. On the other hand, due to inappropriate boundaries, illogical security tactics not only motivate the men to show dangerous behavior to protect their families and waste their energy but also damage intimacy as the most important component of couples' relationship. As a result, the couples' relationship falls apart. Emotional distance can create more distance between couples and more pessimistic attitude for men towards their wives and activate more negative emotions such as morbid jealousy. More morbid jealousy can cause more restriction and constraint for the women, which makes their protection easier. Simultaneously, they use strict control tactics to protect boundaries. Diagram 1 shows the relationship between the variables that eventually leads to marriage failure. 


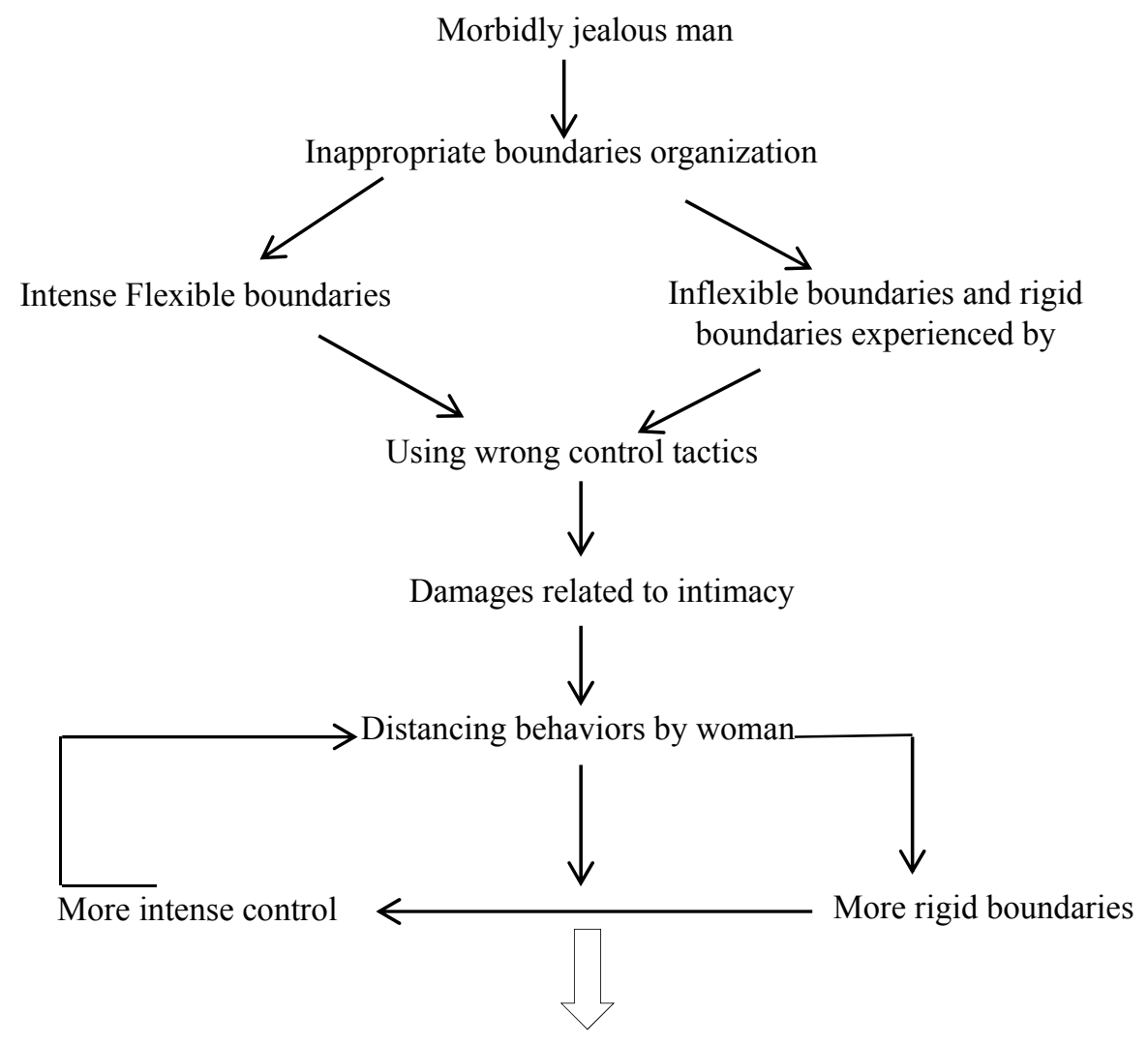

Family collapse

Figure 1. The process of pathology in families with morbidly jealous men

The findings of the study indicated there are other communication damages that can provide the stimulus to other damages. In fact, morbidly jealous men have false beliefs, emotions, and behaviors towards their wives that damage boundaries, control tactics, and intimacy. In total, the researchers found that the men use pessimistic attitude as a defiant mechanism to protect family boundaries and create control tactics. Pessimistic attitude is an obstacle to establish pillars of trust between these men and their wives that contributes to the destruction of a context to trigger mistrust towards their wives. Therefore, couples' life is a painful experience in its different dimensions.

Taking into account the findings, the first signs of morbid jealousy occur in boundaries development. With inappropriate boundaries development, the signs develop to control tactics simultaneously, and the emphatic and logical tactics change to punishment and reprimand. In these conditions, the communication style is dominant and recessive, intimacy is lost, and the relationships will be more of an obligation than passion. With regard to above-mentioned findings, the couple's life is, thus, doomed to failure.

\section{Competing Interests Statement}

The authors declare that there are no competing or potential conflicts of interest.

\section{References}

Amato, P. R., \& DeBoer, D. D. (2001). The transmission of marital instability across generations: Relationship skills or commitment to marriage? Journal of Marriage and Family, 63(4), 1038-1051. https://doi.org/10.1111/j.1741-3737.2001.01038.x

Baxter, L. A. (1988). A dialectical perspective on communication strategies in relationship development.

Blaisure, K. R., \& Allen, K. R. (1995). Feminists and the ideology and practice of marital equality. Journal of Marriage and the Family, 5-19. https://doi.org/10.2307/353812 
Bloch, L., Haase, C. M, \& Levenson, R. W. (2014). Emotion regulation predicts marital satisfaction: More than a wives' tale. Emotion, 14(1), 130. https://doi.org/10.1037/a0034272

Bochner, A. P. (1985). Perspectives on inquiry: Representation, conversation, and reflection. In M. Knapp \& G.R. Miller (Eds.), Hand book of interpersonal communication. Beverly Hills.

Bryman, A. (2004). Social research methods (2nd ed.): Oxford university press.

Bumpass, L. L., Martin, T. C., \& Sweet, J. A. (1991). The impact of family background and early marital factors on marital disruption. Journal of Family Issues, 12(1), 22-42. https://doi.org/10.1177/019251391012001003

Burr, W. R. (1973). Theory construction and the sociology of the family: John Wiley \& Sons.

Canary, D. J, \& Stafford, L. (1992). Relational maintenance strategies and equity in marriage. Communications Monographs, 59(3), 243-267. https://doi.org/10.1080/03637759209376268

Cobb, J. (1979). Morbid jealousy. British journal of hospital medicine, 21(5), 511.

Colaizzi, P. F. (1973). Reflection and research in psychology. Dubuque, IA: Kendall Hunt.

Enoch, M. D., \& Trethowan, W. H. (1979). Some uncommon psychiatric syndromes. John Wright.

Gharehbaghy, F., \& Aguilar-Vafaie, M. (2010). The Role of Marital Conflict and Family Emotional Security in Children's Physical and Psychosocial Health. Iranian Journal of Psychiatry and Clinical Psychology, 15(4), 359-367.

Golafshani, N. (2003). Understanding reliability and validity in qualitative research. The qualitative report, 8(4), 597-606.

Iveniuk, James, Waite, Linda J, Laumann, Edward, McClintock, Martha K, \& Tiedt, Andrew D. (2014). Marital conflict in older couples: Positivity, personality, and health. Journal of Marriage and Family, 76(1), 130-144. https://doi.org/10.1111/jomf.12085

Jocklin, Victor, McGue, Matt, \& Lykken, David T. (1996). Personality and divorce: a genetic analysis. Journal of personality and social psychology, 71(2), 288. https://doi.org/10.1037/0022-3514.71.2.288

Kingham, Michael, \& Gordon, Harvey. (2004). Aspects of morbid jealousy. Advances in Psychiatric Treatment, 10(3), 207-215. https://doi.org/10.1192/apt.10.3.207

Malouff, John M, Schutte, Nicola S, \& Thorsteinsson, Einar B. (2014). Trait emotional intelligence and romantic relationship satisfaction: A meta-analysis. The American Journal of Family Therapy, 42(1), 53-66. https://doi.org/10.1080/01926187.2012.748549

Marazziti, Donatella, Di Nasso, Elena, Masala, Irene, Baroni, Stefano, Abelli, Marianna, Mengali, Francesco, ... Rucci, Paola. (2003). Normal and obsessional jealousy: a study of a population of young adults. European Psychiatry, 18(3), 106-111. https://doi.org/10.1016/S0924-9338(03)00024-5

Moustakas, C. (1994). Phenomenological research methods. Sage. https://doi.org/10.4135/9781412995658

Pirsaghi, F., Nazari, A. M., Naiemi, Gh., \& Shafaie, M. (2015). Marital Conflicts؛ The Role Of Defense Styles And Emotional Schemas. Iranian Journal of Psychiatric Nursing, 3(1), 59-69.

Rajabi, G., Mousavian Nejad, K., \& Taghi Pour, M. (2014). The relationships attachment styles and emotional intelligence with marital satisfaction and marital conflict in married (In Persian). Applied Consultation, 1, 49-66.

Randall, A. K, Post, J. H., Reed, R. G., \& Butler, E. A. (2013). Cooperating with your romantic partner: Associations with interpersonal emotion coordination. Journal of Social and Personal Relationships, 30(8), 1072-1095. https://doi.org/10.1177/0265407513481864

Sanford, K. (2012). The communication of emotion during conflict in married couples. Journal of Family Psychology, 26(3), 297. https://doi.org/10.1037/a0028139

Seidman, I. (2013). Interviewing as qualitative research: A guide for researchers in education and the social sciences. Teachers college press.

Shepherd, M. (1961). Morbid jealousy: Some clinical and social aspects of a psychiatric symptom. The British Journal of Psychiatry, 107(449), 687-753. https://doi.org/10.1192/bjp.107.449.687

Stein, D. J., Hollander, E., \& Josephson, S. C. (1994). Serotonin reuptake blockers for the treatment of obsessional jealousy. The Journal of clinical psychiatry. 
Stieglitz, J., Gurven, M., Kaplan, H., \& Winking, J. (2012). Infidelity, jealousy, and wife abuse among Tsimane forager-farmers: testing evolutionary hypotheses of marital conflict. Evolution and Human Behavior, 33(5), 438-448. https://doi.org/10.1016/j.evolhumbehav.2011.12.006

Storaasli, R. D, \& Markman, H. J. (1990). Relationship problems in the early stages of marriage: A longitudinal investigation. Journal of Family Psychology, 4(1), 80. https://doi.org/10.1037/0893-3200.4.1.80

Vauhkonen, K. (1968). On the pathogenesis of morbid jealousy with special reference to the personality traits of an interaction between jealous patients and their spouses. Acta psychiatrica Scandinavica. Supplementum, 202, 2 .

\section{Copyrights}

Copyright for this article is retained by the author(s), with first publication rights granted to the journal.

This is an open-access article distributed under the terms and conditions of the Creative Commons Attribution license (http://creativecommons.org/licenses/by/4.0/). 